\title{
METRAZOL TOLERANCE IN A "NORMAL" VOLUNTEER POPULATION 1
}

\section{An investigation of the potential significance of abnormal findings}

\author{
E. RoDin, M.D. \\ Department of Psychiatry (Mental Health Research Institute and \\ Section of Electroencephalography) University of Michigan, \\ Ann Arbor, Mich.
}

(Received for publication: January 17, 1958)

The slow intravenous injection of a 5 or 10 per cent solution of Metrazol (pentylenetetrazol) has been widely accepted as a means to induce either electroencephalographic seizure discharges or overt clinical seizures in patients suspected of having a convulsive disorder.

The method of estimating the "convulsive threshold" of patients was originally suggested by Ziskind et al. (1947) and a similar method was advanced by Cure, Rasmussen, and Jasper (1949). Gastaut added in 1950 intermittent photic stimulation of the retina, at the time of Metrazol administration, to the procedure and was able to demonstrate a further lowering of the Metrazol thresholds in certain patients. The initial hope that only epileptic patients would be activated by relatively low doses of the drug was, however, not borne out, since it was already evident from Ziskind's data that a considerable overlap between diagnostic groups exists. Gastaut stated that "photo-Metrazol stimulation of the brain is not an electroencephalographic method for the diagnosis of epilepsy", but he felt that "it is a elinical neurophysiological test which provides a method for the exploration of certain sub-cortical structures among which the most important are those of the diencephalon and most especially of the thalamus". He observed that three different groups of patients tended to have low thresholds. These were: (1) the group of idiopathic epileptic patients; (2) the schizophrenic patients; and (3) patients with hysteria.

1 This project was in part supported by United States Public Health Service Grant No. 1379.
Further studies revealed that Metrazol produced changes not only in patients with neuropsychiatric disorders, but also in a certain percentage of normal control subjects. The largest series reported in the literature is that of Buchthal and Lennox (1953), who investigated 682 Air Force applicants. These authors observed that in 64 per cent of this group no EEG changes resulted from Metrazol administration, while in 22.4 per cent definite paroxysms were induced, and in 18 subjects grand mal seizures were noted during the procedure. The maximun dose any subject received was $350 \mathrm{mg}$. When the subjects were separated on the basis of individual evidence suggesting "neurological involvement", it became apparent that 53 per cent of the neurologically involved subjects and $1 \tilde{y}$ per cent of the non-involved group showed positive results. The authors felt that their results confirmed the diagnostic value of Metrazol injection in epilepsy.

The second largest series of normal subjects was reported by Moore, Kellaway, and Kagawa (1954). One hundred and twenty subjects were tested "who met strict eriteria of normality" and it was found that 35 per cent of these showed definitely positive results. The maximum dose any subject received was $500 \mathrm{mg}$. The authors did not find any correlation between body weight and Metrazol threshold, but did observe that individuals below the age of 30 were more apt to have positive reactions. The authors concluded that even a spike-wave response cannot reasonably be considered evidence of a convulsive disorder. 
Kershman reported in 1951 on a somewhat smaller series of normal controls. $\mathrm{He}$ investigated 31 normal college students by means of photic stimulation and Metrazol injection, and found that the average threshold was $4.2 \mathrm{mg} / \mathrm{kg}$., not $8.0 \mathrm{mg} / \mathrm{kg}$. as suggested by Gastaut. This threshold was in fact lower than the threshold observed in schizophrenic or psychoneurotic patients. Fuglsang-Fredricksen (1952), using Metrazol alone and taking $350 \mathrm{mg}$. as the cut-off point, observed paroxysmal discharges in only 1 of 63 normal subjects; 8 of these subjects had paroxysms when the dose was increased to a maximum of $500 \mathrm{mg}$. (23 of the 63 subjects received $500 \mathrm{mg}$. and 40 received $350 \mathrm{mg}$.) .

The most recent report is that published in 1957 by Baker, Klass, and Walter, who gave Metrazol to 51. Air Force volunteers, until either spike-wave discharges appeared in the EEG or 1,000 mg. had been given. These discharges were obtained in 43 subjects with an average amount of $475 \mathrm{mg}$., or if related to body weight, $6.9 \mathrm{mg}$. per kilogram. The range of dosages that produced discharges was from $180 \mathrm{mg}$. to $900 \mathrm{mg}$. of Metrazol, or 2.5 to $11.8 \mathrm{mg}$. per kilogram. The authors concluded that since spike-wave discharges and other paroxysmal discharges oceur regularly in normal subjects, it seems unwarranted to set an arbitrary level to distinguish "normal" from "abnormal", or non-epileptic from epileptic.

It is evident from the foregoing that there exists a fair amount of discrepancy in objective findings as well as in the interpretation of the findings by individual authors. Although considerable attention has been paid to the EEG changes that occur during Metrazol administration, relatively little information has appeared in the literature about the subjective symptoms which patients or subjects may notice as a result of the drug. Clinical experiences with the Metrazol test, either in conjunction with photic-stimulation or when the drug was given alone, showed that there is a considerable difference between patients in the amount of subjective discomfort induced by the procedure. This reaction is largely unrelated to any changes in the EEG and is also only in part related to the total dose, although in general the amount of discomfort increases with the quantity of medication given. Some patients, however, observe a profound subjective reaction consisting of "dizziness" (which may be subjective or objective vertigo, light headedness, or a sensation of impending loss of consciousness) profound tension, and anxiety with only $50 \mathrm{mg}$., while other patients may not experience any marked changes up to 400 or $500 \mathrm{mg}$. levels. The types of symptoms which are induced are likewise quite variable and may range from simple muscle tension and muscular twitchings, without anxiety, to profound vertigo, panic sensations, changes in body image, or hallucinatory experiences.

Since it was apparent from the literature and the personal experience of this author that some normal control subjects may respond to Metrazol in a way that might be regarded as pathological, it was of interest to investigate whether these "normal" individuals differed from the rest of the sampled normal population in any other way.

\section{MATERIAL AND METHODS}

Forty normal control subjects were investigated; the majority (37) were students at the University of Michigan. There were 12 women and 28 men, ranging in age from 19 to 32 years. The subjects volunteered for the examination, and as an incentive they received a financial reward. They were informed that the purpose of the investigation was to find any possible correlation between an individual's personality structure, past history, and the electric potentials of his brain during rest and while under the influence of a drug. The volunteers were not informed about the type of drug they were to receive, but were told that they might or might not experience a variety of subjective reactions. They were encouraged to express freely their symptoms during drug administration, however foolish a symptom might appear to them at the time when they were experiencing it. No attempt was made to screen subjects for the absence of neurologie or psychiatric disorders, but every attempt was made to get a complete and re- 
liable medical history, with the help of a specially designed questionnaire. Major emphasis was placed on family history of nervous breakdown or epilepsy and personal history concerning birth, febrile convulsions, the ocanrence of temper tantrums or a problem with bed-wetting in childhood, serious head injuries or major illnesses, recurrent identical nightmares, sleep-walking, and fainting spells. The subjects were also asked, on the same questionnaire, to answer with yes or no whether they felt that they were becoming anxious relatively easily and whether they had "considered seeing a psychiatrist for a personal problem you may have had or still have". Finally they were asked to encircle one or tion of Metrazol intravenously at the rate of $50 \mathrm{mg}$. per min. until either marked EEG changes developed or the subject was so uncomfortable that further administration was not feasible. Each $50 \mathrm{mg}$. dose was given rapidly. Initially $1,000 \mathrm{mg}$. was the amount available in the syringe. However, no subject received more than $650 \mathrm{mg}$. for the above mentioned reasons. After 6 subjects had been tested, with a grand mal seizure occurring in one at a Metrazol level of $550 \mathrm{mg}$., an arbitrary limit of $500 \mathrm{mg}$. was set for the total dose. A syringe containing $250 \mathrm{mg}$. of amytal was kept in readiness to prevent the occurrence of seizures. It was administered when spike-wave discharges occurred or in cases

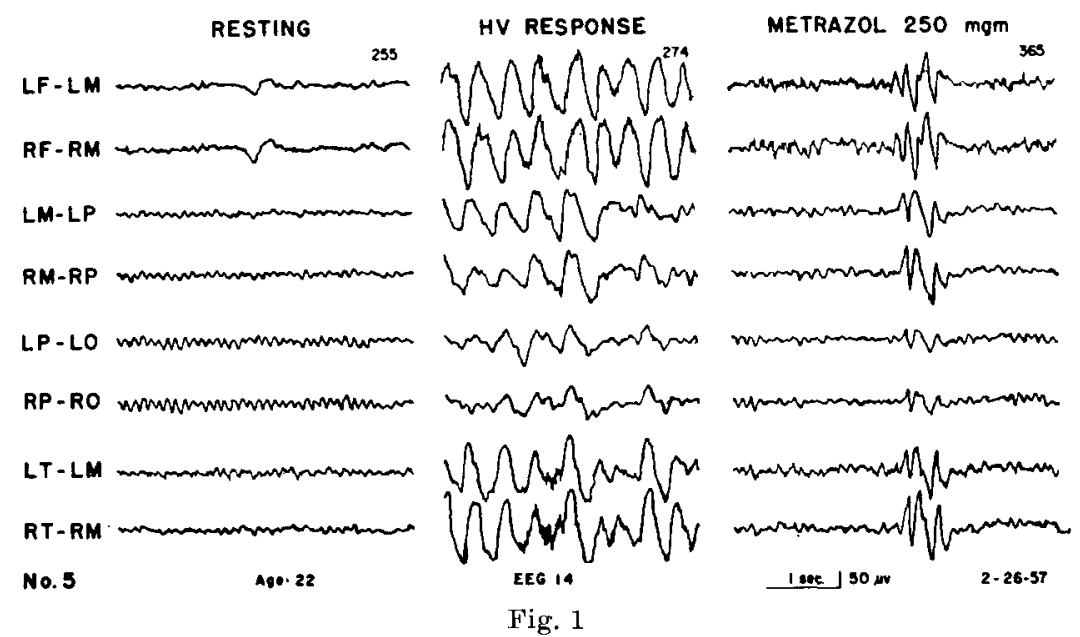

more of the following adjectives which seemed to fit their personality structure best: quiet, reserved, shy, outgoing, nervous, tense, highstrung, calm, easygoing, outwardly calm but with inner turmoil, happy, easily frustrated, depressed.

The procedure of investigation was as follows: the volunteer was tested psychologically for a period of one full day and an additional forenoon with a battery of different tests. On the afternoon of the second day a 45. min. standard routine EEG recording was obtained, including a $3 \mathrm{~min}$. period of hyperventilation followed by intermittent photicstimulation with flash rates varying between one and 30 per sec. After these preliminary studies, the subject received a 5 per cent solu- of considerable subjective discomfort. Photic stimulation at a rate of 15 flashes per sec. was carried out intermittently from a Metrazol level of $100 \mathrm{mg}$. on. EEG recording was continued for $10 \mathrm{~min}$. after the total amount of drug had been given. The subject was then questioned about the symptoms he had experienced during drug administration, and it was after this interview that he was asked to fill in the previously mentioned questionnaire. He was requested specifically to be as frank, detailed, and honest as possible, since inadequate or incorrect statement would defeat the purpose of the experiment. The results of the questionnaire were then gone over with the individual in order to clarify possibly ambiguous answers. Finally, a neurol- 
ogical examination was performed and the volunteer was then dismissed.

On the following day an essentially similar questionnaire regarding birth and early childhood was sent to the parents, with the subject's consent, in the hope that more back- same scale was applied to the hyperventilation response.

The Metrazol responses were likewise graded on a 4-point seale. The objective response was regarded as grade 1 when no EEG changes or only slight scattered theta

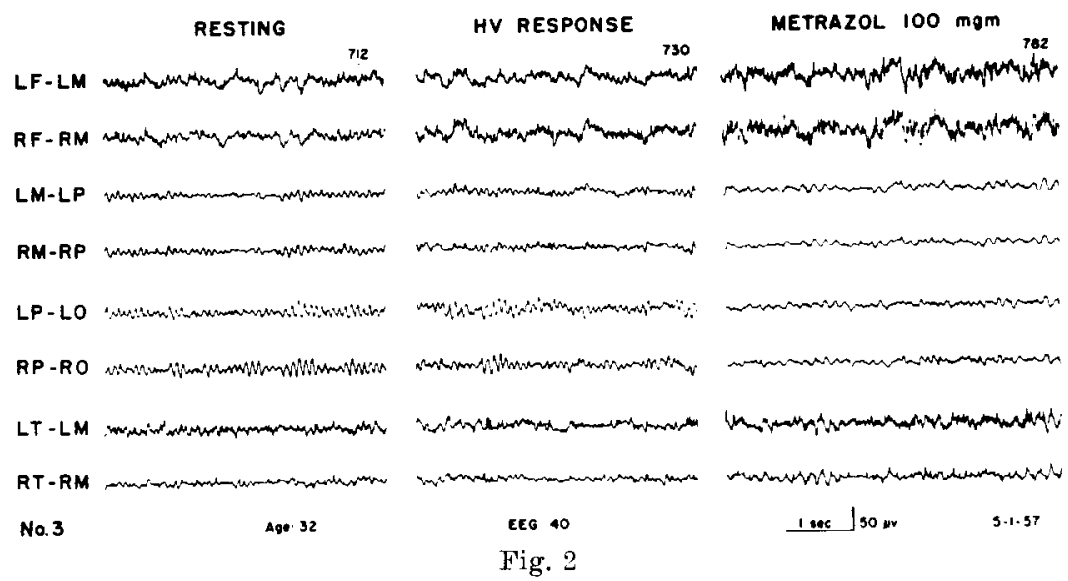

ground information would thus become available.

The EEG's were recorded on a Grass Model III-D Electroencephalograph. Sixteen electrodes were employed in both mono-polar and bi-polar connections. A Grass Model PS activity had occurred; 2 , when definite scattered theta activity made its appearance; 3 , when either high voltage diffuse paroxysms appeared (fig. 1) or when 5 to $7 \mathrm{c} / \mathrm{sec}$. became the dominant frequeney for at least 4 to $5 \mathrm{sec}$. at a time (fig. 2 ); and 4 , when atypical spike-
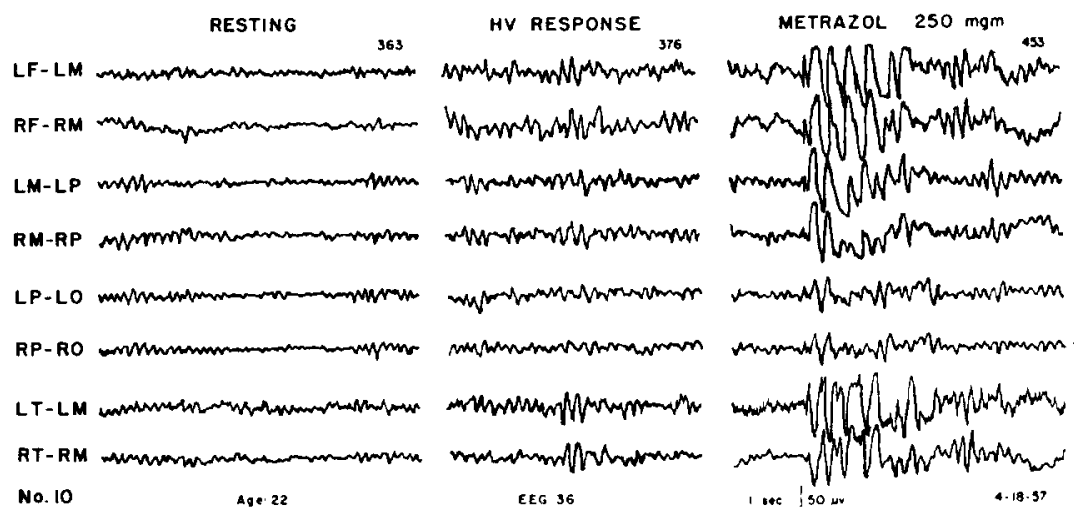

Fig. 3

1 stimulator was used for photic stimulation, on intensity-setting 4 (approximately 375,000 candle power).

The resting EEG's were rated on a 4-point scale: 1 meaning normal, 2 borderline, 3 mildly abnormal, 4 definitely abnormal. The wave discharges (fig. 3) or grand mal convulsions oceurred. The subjective response was regarded as grade 1 when the subject experienced some muscular tension, twitching of eyelids, nervousness, pain at the injection site or "a fumny smell". A grade 2 response was 
the subject's complaint of dizziness which was either light headedness or a moderate spinning sensation, a slight rocking feeling, some numbness in the arm in which the injection was made, or some nausea. A response was graded as 3 when marked whirling occurred or a sensation of floating, mental haziness, numbness (not restricted to the arm of injection) or a sensation of impending loss of conscionsness. A grade 4 response consisted of a sense of mental confusion, subjective inability to move, crude visual or auditory hallueinations, a change in body image, or inability to complete the test for other subjective reasons.

\section{METRAZOL TOLERANCE vs. SYMPTOMS INDEX}

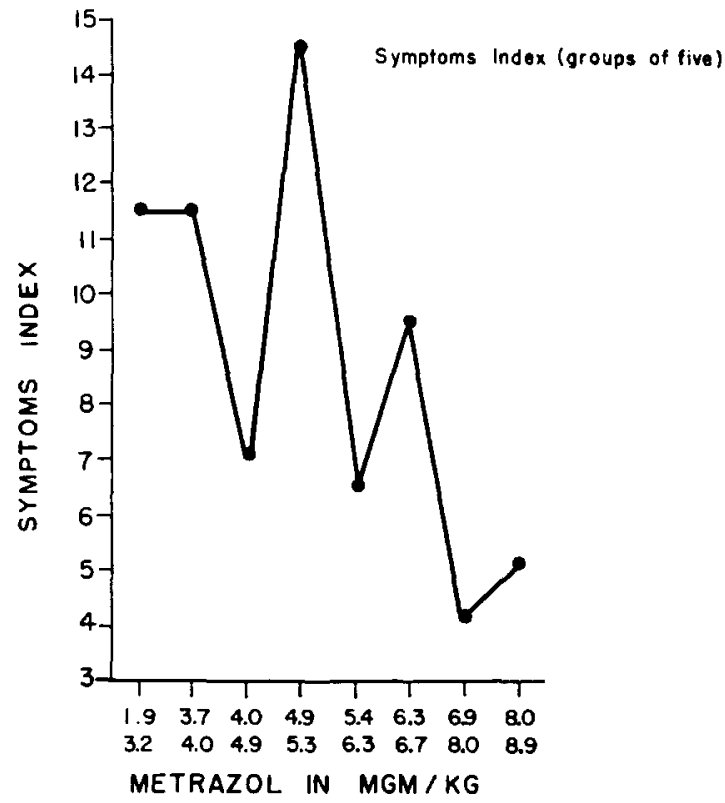

Fig. 4

The total dose of Metrazol which each subject had received was converted into mg. per kg. of body weight, and this value was called "Metrazol tolerance". The data were then subjected to statistical analysis for determination of significant eorrelations between the different variables.

\section{RESULTS}

Only the results in relation to EEG findings, past history, and self-appraisal will be presented here. The results of psychological testing and their correlation with the Metrazol responses will be published separately.

Table I shows the results of the investigation in regard to resting EEG, hyperventilation response, and objective and subjective Metrazol responses. The abnormalities in the resting EEG consisted mainly of unilateral or shifting bilateral temporal sharp theta dis-

TABIE I

\begin{tabular}{lrrrr} 
& $\begin{array}{c}\text { Rest. } \\
\text { EEG } \\
\%\end{array}$ & H V & $\begin{array}{c}\text { Obj. } \\
\text { Met. } \\
\%\end{array}$ & $\begin{array}{c}\text { Subj. } \\
\text { Met. } \\
\%\end{array}$ \\
\hline Responses 1 & 42.5 & 72.5 & 20.5 & 7.5 \\
Responses 2 & 32.5 & 15.0 & 15.0 & 20.0 \\
Responses 3 & 22.5 & 12.5 & 37.5 & 52.5 \\
Responses 4 & 2.5 & .0 & 25.0 & 20.0
\end{tabular}

charges; the one subject with a grade 4 record showed long periods of 5 to $6 \mathrm{c} / \mathrm{sec}$. activity as the dominant frequency which was not attributable to drowsiness. Since no seizure patterns oceurred during hyperventilation and the build-up induced by the overbreathing never persisted longer than one minute after cessation of deep breathing, no response was graded as 4 . Two of the subjects with a grade 4 objective Metrazol response had a grand mal seizure. One seizure occurred at a Metrazol level of $550 \mathrm{mg}$. in spite of amytal administration during the pre-seizure build-up. The other seizure occurred at a level of $250 \mathrm{mg}$. The two seizures were very similar clinically and electroencephalographically. There were no focal features. The head was

TABLE II

DISTRIBUTION OF SUBJECTIVE VERSTS OBJECTIVE RESPOXSES

\begin{tabular}{|c|c|c|c|c|c|}
\hline Subjective & 1 & 2 & 3 & 4 & Total \\
\hline \multicolumn{6}{|l|}{ Objective } \\
\hline 1 & 0 & 3 & 3 & 3 & 9 \\
\hline 2 & 1 & $2(1-f)$ & $3(1-f)$ & 0 & $6(2-f)$ \\
\hline 3 & 1 & $3(1-f)$ & $7(4-f)$ & $4(2-f)$ & $15(7-f)$ \\
\hline 4 & $1(1 \cdot f)$ & 0 & $8(1-f)$ & $1(1 \cdot f)$ & $10(3-f)$ \\
\hline Total & $3(1-\mathbf{f})$ & $8(2-f)$ & $21(6-f)$ & $8(3-f)$ & $40(12-f)$ \\
\hline
\end{tabular}


kept in the midline and the mouth remained open even during the clonic phase of the seizure. Post-ictally there was profound memory loss and disorientation as to time and place. This disappeared within a period of an hour. The subjects were not aware that they had had a seizure but assumed that they had just "passed out" momentarily.

Table II shows the distribution of the subjective and objective responses. The figures in brackets indicate the number of female subjects. The type and frequency of subjective reaction can be seen in table III. The "funny

\section{TABLE III}

TYPE OF SYMPTOMS WHICH OCCURRED IN MORE THAN ONE SUBJECT DURING METRAZOL ADMINISTRATION

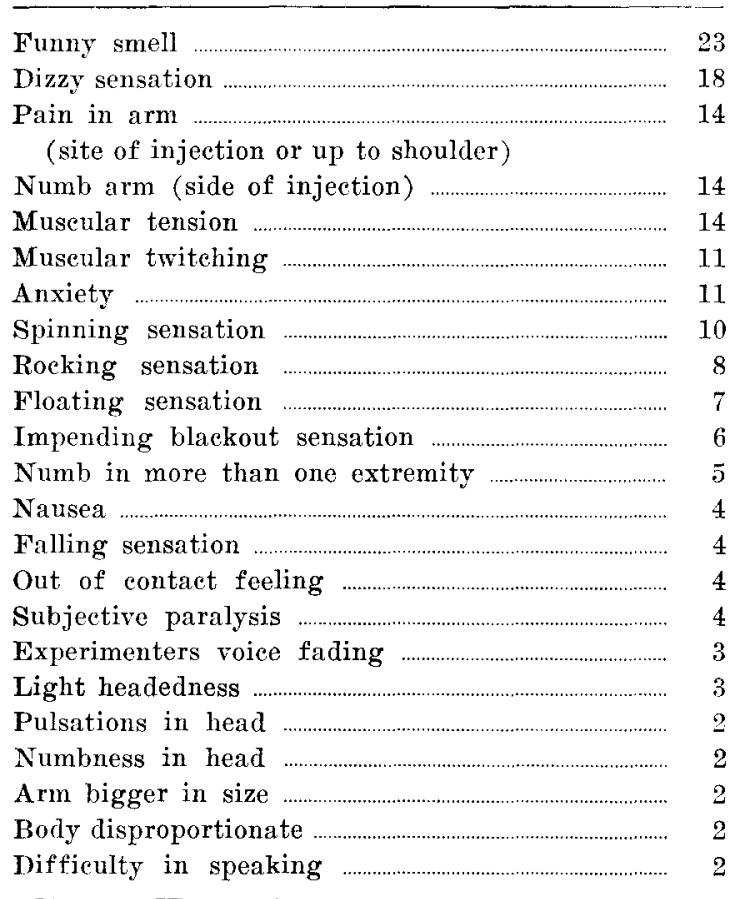

smell" which subjects noted was quite variable and was described as differently as: sweet, musty, foul, oily, burnt vaseline, perfume, vanilla, burning butterscotch, black-walnut flavor, and the like. The following symptoms are not listed in the table because each occurred only once among all 40 patients: a pressure sensation in the head, a dead feeling in the head, a prickly sensation in the head, dryness of the mouth, sweatiness of the hands, pounding of the heart, fear of losing control, absence of bodily perceptions, drowsiness, inability to think, shaky feeling, a sensation as if the various parts of the body were disconnected, a sense of confusion, a visual hallucination of a blue cloud, an auditory hallucination of the crying sound of a baby doll, a sensation of happiness, a sellsation of being carefree, and a calm feeling. It should be pointed out that some of the mentioned symptoms may have occurred more often, but care was taken in the interview not to ask any leading questions which might have added an element of suggestion. The individual was merely asked to recount as accurately as possible the types of sensations which he had experienced. In the following paragraphs, examples are given of the various subjective responses which occurred.

The report of subject No. 37 can be taken as an example of a No. 2 response. The total dose of Metrazol administered was $650 \mathrm{mg}$. $(8.6 \mathrm{mg} / \mathrm{kg}$.). The subject experienced muscle tension, some anxiety, and "worry about what was going to happen", some dizziness which was not true vertigo but rather a "swimming sensation in the head", a pulsating sensation in the head and in the body, a dry feeling in the mouth, and pain in the left arm and shoulder (the arm used for injection). There was no change in the EEG.

Subject No. 13 showed a spike-wave response objectively; the subjective response quoted in the following paragraph was regarded as 3. The subject thought that the experience was frightening, "you didn't like what was happening to you but you didn't want to do anything about it". "I don't like situations where I'm not in control of it". She noted a numbness in her left shoulder "like having no feeling, as if it was asleep, then the right one got the same way". Then she "became conscious of a numbness around the waist", then "I got more seared than I've ever been in my life, so seared, really seared. This kept building up. Then I thought this is ridiculous and then it was all right. Then you started getting peaceful and didn't care anymore. I didn't feel at all in control of 
myself just before I opened my eyes" (the subject was ordered to open her eyes at the moment the spike-wave burst occurred). The subject had received a total amount of $250 \mathrm{mg}$. of Metrazol (4.5 mg/kg.); no amytal was given in this particular case.

The response in subject No. 18 was graded as 4 . After the first $50 \mathrm{mg}$. had been given, the patient experienced a dizzy sensation, a feeling as if he were suspended in space. His head felt light; he felt "sort of dead in the head". He had a sensation of rocking up and down and from side to side. This then developed into vertigo. He felt as if he were going in a counter-clockwise direction. $\mathrm{He}$ noticed perspiration in feet and legs and for a while it seemed "as if my body and my head were separate from each other". He then noted a sensation of "going up in a spiral, spinning like"', and the speed of spinning increased as the Metrazol dose was stepped up. Photic stimulation during the Metrazol test produced a sensation as if the light were steadily getting brighter and emitting waves. At one time he felt as if he were in a strange place, then as if he were rocking around in a boat. However, at all times, his emotional attitude was one of being "carefree", "felt that I had no worry", and he stated that although he may have become slightly anxious during the spinning sensation, this was hardly noticeable. No muscle tension was induced. He had also noticed at one time a numbness involving mostly the left arm (site of injection), a sensation as if some parts of his body were not connected with each other, and especially an absence of physical sensations from his head, as if the head were not part of his body. The total amount given in this instance was $500 \mathrm{mg}$. $(5.2 \mathrm{mg} / \mathrm{kg}$.) and there was $n o$ change in the EEG.

Computation of the mean Metrazol tolerance for all subjects gave a value of 5.5 $\mathrm{mg} / \mathrm{kg}$. The mean threshold of the subjects in whom drug administration was stopped because of spike-wave responses, was $4.0 \mathrm{mg} / \mathrm{kg}$. The extremes for spike-wave occurrence were $1.9 \mathrm{mg} / \mathrm{kg}$. (150 mg.) and $6.7 \mathrm{mg} / \mathrm{kg}$. (550 mo.). In 3 instances spike-wave responses were triggered by photic stimulation. In the other 7 they occurred independently of photic stimulation. The mean tolerance value for the subjects in whom the drug was arbitrarily stopped at $500 \mathrm{mg}$. was $7.3 \mathrm{mg} / \mathrm{kg}$. with extremes ranging between $6.1 \mathrm{mg} / \mathrm{kg}$. and 8.9 $\mathrm{mg} / \mathrm{kg}$.

The neurological examination was negative in all subjects, but 8 subjects had a positive history for physical difficulties. These included "mild concussion" in 3, prematurity. breech birth, prolonged blueness at birth and severe colitis in infancy, severe measles associated with left facial palsy, being "knocked unconscious while playing" in childhood.

TABLE IV

FREQUENCY OF SYMPTOMS BY HISTORY

\begin{tabular}{|c|c|}
\hline 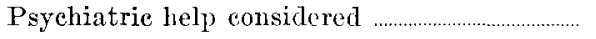 & 17 \\
\hline Sleep walking ……................... & 11 \\
\hline 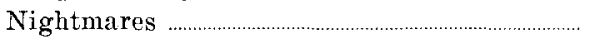 & 10 \\
\hline 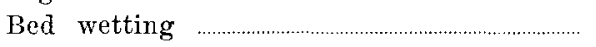 & 9 \\
\hline Family history positive & $7+3^{*}$ \\
\hline Fainting & 7 \\
\hline Tantrums & $6+2^{*}$ \\
\hline No symptoms. & 8 \\
\hline
\end{tabular}

* See text for +3 and +2 figures.

Table IV shows the frequency of symptoms and positive family history in the total group. This part of the historical information was treated statistically, but information on the physical difficulties mentioned above was not so treated, because such difficulties occurred only in isolated instances and all of these subjects had in addition given positive answers to at least one of the symptoms described in table IV. When the numbers of positive answers of the type presented in table IV were added, a "symptom index" was arrived at for any given individual. If the statements from the parents' questionnaire agreed with the subject's questionnaire, a numerical value of 1 was assigned to each positive answer; if they disagreed a numerical value of 0.5 was assigned to the symptom in question. For example, a subject might indicate a family history positive for nervous breakdown while the question was not answered on the otherwise complete parental questionnaire, or the subject might deny having had temper tantrums 


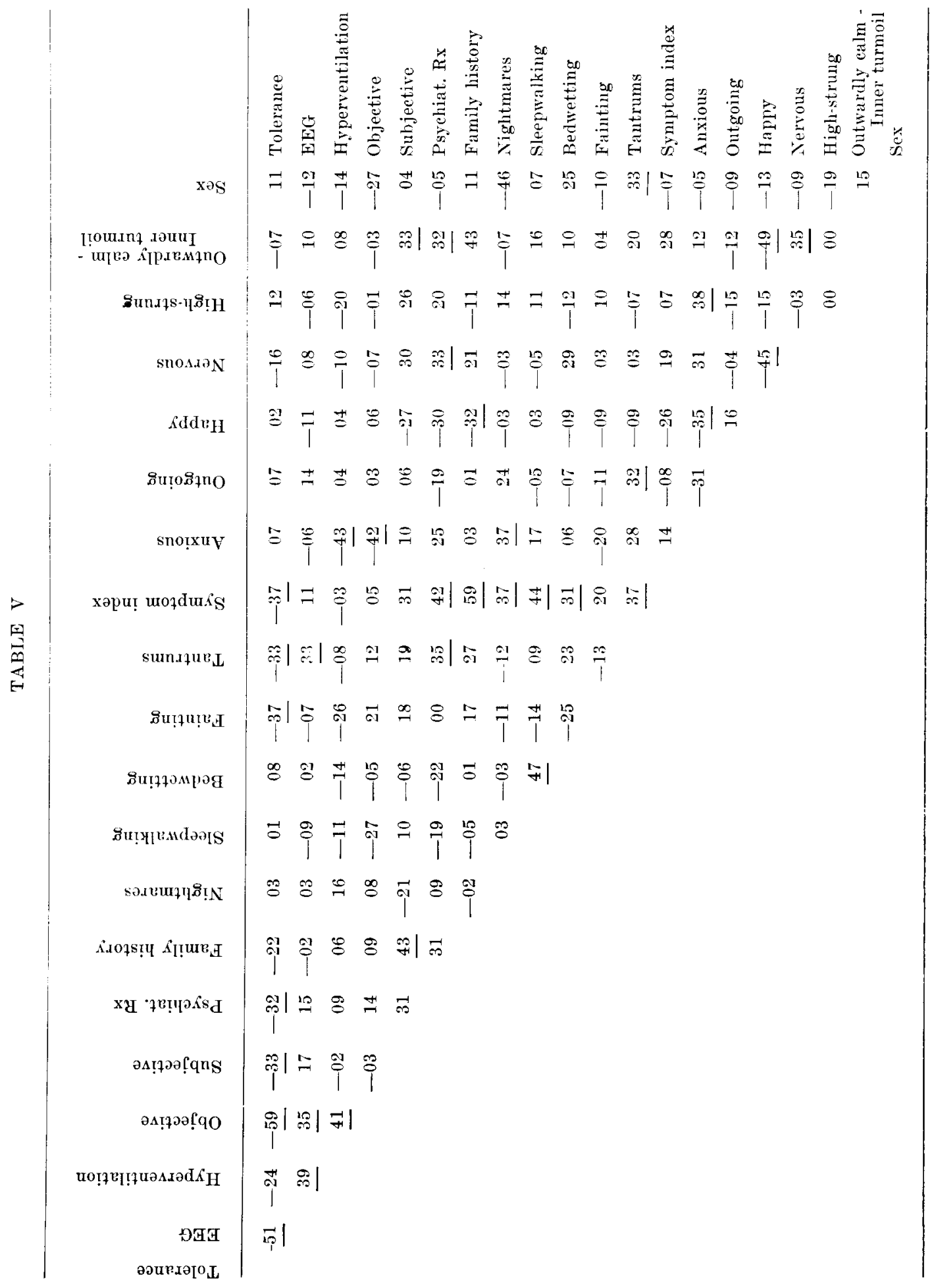


while the parental questionnaire indicated that there had been a problem in this respect. This is shown in table IV as the +3 and +2 figures. In general, however, there was remarkable agreement between the subjects' and the parents' statements. The maximum number of positive answers for a given subject was 5 . When this symptom-index was plotted against Metrazol tolerance, it became apparent that a striking correlation existed. The lower walking, bed-wetting, fainting, temper tantrums, anxious easily, outgoing, happy, nervous, high-strung, and outwardly calm with inner turmoil. The correlation matrix is given in table $V$. The underlined numbers are statistically significant at the 5 per cent level. Tables VI and VII give a summary of the statistically significant positive and negative correlations. An example of positive correlation would be that subjects having an abnormal

TABIE VI

POSITIVE CORRELATIONS SIGNIFICANT AT 5 PER CENT LEVEI,

\section{Resting EEG}

$\mathrm{HV}$ response

Objective Metrazol response

Subjective Metrazol response

Psychiatric treatment considered

Family history positive

Nightmares

Sleep walking

Tantrums

Outwardly calm with inner turmoil
HV response, objective Metrazol response, tantrums Objective Metrazol response

Resting EEG, HV response

Family history, outwardly calm with inner turmoil Symptom index, tantrums, nervous, outwardly calm with inner turmoil

Subjective Metrazol response, symptom index

Symptom index, anxious easily, female sex

Bedwetting, symptom index

Male sex, outgoing

Subjective Metrazol response, psyehiatric treatment considered, nervous the drug tolerance, the higher the symptom index tended to be (fig. 4).

All of the following variables were then correlated against each other on the IBM 650 computer: sex, resting EEG, hyperventilation response, Metrazol tolerance, objective and subjective Metrazol response, symptom index, whether psychiatric treatment had been considered, family history, nightmares, sleep- resting EEG tended to have in this series an abnormal hyperventilation response, an abnormal objective Metrazol response, and a history of temper tantrums. An example of negative correlation would be the observation that subjects with a high Metrazol tolerance tended to have a low rating of their resting EEG's, a low rating of the objective and subjective Metrazol responses, they did not desire to see a

TABLE VII

NEGATIVE CORRELATIONS SIGNIFICANT AT THE 5 PER CENT LEVEL

Metrazol tolerance

HV response

Objective Metrazol response

Psychiatric treatment considered

Family history positive

Fainting

Happy

Nervous

Outwardly calm with inner turmoil
Resting EEG, objective Metrazol

response, subjective Metrazol

response, psychiatric treatment considered, fainting, tantrums, symptom index

Anxious easily

Anxious easily

Metrazol tolerance

Happy

Metrazol tolerance

Anxious easily, family history positive

Happy

Happy 
psychiatrist, did not have fainting spells or temper tantrums, and had a low symptomindex.

\section{DISCUSSION}

The findings obtained in this investigation amply support the statements of other authors about the occurrence of spike-wave responses at relatively low drug levels in some normal subjects. The different percentages of oceurrence of paroxysmal or spike-wave responses in normal control groups are not large enough that they could not be accounted for by the differences in the total dose used as arbitrary cut-off point and the rate of administration. The difficulty in selecting any particular EEG sign as end point and thus as the "convulsive threshold" was pointed out in a report by Ulett et al. (1955).

The present study reveals some new findings, however, which are worthy of comment. The fact that the drug tolerance in $\mathrm{mg}$. per $\mathrm{kg}$. of body weight correlated significantly with the condition of the resting $\mathrm{EEG}$, hyperventilation response, and the amount of positive historical information regarding the presence of some neuropsychiatric symptoms, indicates that Metrazol tolerance is indeed a useful measurement. Its correlation with both the objective and subjective response to Metrazol is of course to be expected, by definition. The finding that it also correlated with an individual's interest in obtaining psychiatric help indicates that this factor has to be considered in evaluating a "normal" population. It appears likely that some of the subjects may actually at some date visit a psychiatrist and thus cross the bridge between being regarded as a "normal control" and as a "patient". One might speculate therefore that the test may possibly have predictive potential regarding the likehood of present or future overt illness in some subjects. It should be pointed ont, however, that such prediction is not possible when either the subjective or objective drug response is taken alone, since neither of these show by themselves the above eited correlation. The subjective response per se, however, correlated with a positive family history of psychiatric disorders.
The search for factors which relate to the occurrence of the spike-wave response or other abnormalities in the EEG as a result of Metrazol administration was not too rewarding. Correlation was obtained between the objective Metrazol response and the resting EEG, and the hyperventilation response; however, this relationship was well known in the past. In addition only one new correlation was found which is at first glance somewhat difficult to evaluate. This is the fact that 8 of 10 subjects with spike-wave responses did not regard themselves as "getting anxious easily". Although the neurophysiological principles involved in this finding are unknown at the present, it might shed some light on certain observations reported in the literature. Gastaut (1950) reported low thresholds in hysterical and schizophrenic patients. The "belle indifference" of the hysterical and the "flat affect" of the schizophrenic patient are classical diagnostic landmarks in the two conditions. These patients are in general not anxious. Another group of psychiatrie patients, who are as a rule rather anxious, however, namely the psychoneurotic group, have according to Kershman (1951) higher thresholds for Metrazol responses. Kershman reported likewise a drop in the Metrazol threshold of schizophrenic patients after leucotomy, a procedure which is well-known to decrease anxiety in the patient. In these instances the fact of operative trauma would of course have to be considered also as a contributing factor in the lowering of the threshold.

While most of the information in this report is of a statistical nature, it is also inportant to look at the individuals themselves who give an extremely positive response to the drug in the form of a convulsive seizure. The subject who had a seizure with $250 \mathrm{mg}$. of the drug $(4.0 \mathrm{mg} / \mathrm{kg}$.) had fainted twice recently for no apparent reason and there is therefore the possibility that these fainting spells might have been on the basis of a convulsive disorder. The other subject who had a generalized seizure at a $550 \mathrm{mg}$. level (6.7 $m$ g. $/ \mathrm{kg}$.) was an adopted child and there is no information available about possible convulsive disorders in his genetic parents. 
The meager correlation of the spike-wave response with other variables indicates that the most important factors have not been sampled. Fainting did not correlate statistically, but of 7 subjects who had fainted, 3 showed spike-wave responses while 3 others developed grade 4 subjective responses. This would tend to corroborate the clinical impression that at least two different types of pathophysiological mechanisms are involved in the production of this symptom in different individuals.

It was somewhat surprising to see the large proportion of "psychiatrically tinged" subjects in this group, and this raises the serious question of a bias in the sampled group. It could be introduced by the possibility that largely those individuals would volunteer for a study of this sort who are interested for personal reasons to learn more about themselves. This bias, if it indeed exists, is not easily overcome and will be inherent in any volunteer group, however rigid the screening precautions may be. Sereening subjects to meet "strict criteria of normality" as reported in the Moore, Kellaway, and Kagawa report, is practically impossible, since it is easier for a subject to deny any of the symptoms which were mentioned here than to admit to them. It was felt, however, that some attempt should be made to find out how representative the group tested in this study was for the average college population. For this reason the same questionnaire which had been filled out by the test group was sent to a completely random selection of students with an explanatory letter asking them to answer all questions as truthfully as possible and not to sign the questionnaire. The random selection was accomplished by picking names alphabetically from the student register. The first two and last two persons of each letter of the alphabet were considered. Students above 30 years of age were subsequently eliminated. Eighty-two questionnaires were sent out. Fifty-eight students returned the questionnaire properly filled in, two sent it back blank, and three students were not located at the address given. The first 40 questionnaires which were returned were regarded as the comparable sample. The mean symptom-index in the test group had been 1.7 and in the letter group 1.4. In the test group there were 17 subjects who had considered psychiatric help, in the letter group 13. A positive family history was present in at least 7 and possibly 10 instances in the test group and in 7 instances in the letter group. There is thus some evidence of a bias toward more symptoms in the test group, but it is not as large as one might have anticipated. A criticism might of course again be leveled against the results obtained by letter since there was not 100 per cent return of letters, and it is possible that those students who did not answer the letter might have the lowest symptom-index. It is, however, somewhat unlikely that students who do not even care to fill in a questionnaire and mail it in a self-addressed envelope would be the ones who would volunteer for experiments on themselves.

The high percentage of subjects in the test and letter group, 40.2 per cent and 32.5 per cent respectively, who had considered obtaining psychiatric help is interesting in relation to other studies about the incidence and distribution of psychiatric symptoms in the general population. A study of this sort was carried out in a small New England town by Leighton (1956), and it was observed that 37 per cent of the sample were found to have a psychiatric illness. A similar conclusion was arrived at by Cole et al. (1957), who reported recently that a survey of eight city blocks in Salt Lake City, Utah, revealed that roughly one-third of the adult population sampled seemed to have some kind of specific mental illness, while about one-half of the families sampled contained at least one mentally ill person. These figures underscore quite markedly the problem one has to meet in evaluating the "normal subject". This difficulty increases when one works with a volunteer group of subjects. A study by Lasagna and von Felsinger (1954) highlighted this situation clearly. Of 56 volunteers, 25 (44.6 per cent) showed evidence of psychological maladjustment. If one accepts a positive answer to the question about psychiatric help as suggestive of psychological 
malajustment, our finding of 40.2 per cent is quite similar. These observations suggest that if a finding which one would ordinarily expect in a patient only is encountered in an EEG tracing spontaneously or as a result of $\mathrm{Me}$ trazol in a "normal subject", it should not simply be disregarded as a false positive observation. On the contrary, an effort should be made to uncover the reasons for the positive response. If no overt neuropsychiatric illness were to be found, it would probably be more advisable to regard this individual as "at present asymptomatic" rather than simply "normal". Since it is known that genetic factors play an important part in EEG findings these individuals might conceivably transmit their abnormalities to their offsprings, and some sudden oceurrences of convulsive disorders or mental illnesses in seemingly healthy families might be accounted for in this way. This problem deserves further investigation.

The electroencephalographer is still confronted, however, with the problem of how to interpret the occurrence of spike-wave responses, or even of a grand mal seizure which is non-focal in its onset, at low levels of Metrazol in a patient who is sent for diagnostic (valuation of his spells. It would seem justified to state in these instances in the report to the clinician that the patient has shown evidence suggestive of a "convulsive tendency" in his electroencephalogram, but a definitive diagnosis of convulsive disorder should still be made on clinical grounds.

Focal attacks, either grand mal seizures with focal onset or focal motor or sensory seizures as well as temporal lobe seizures, have not occurred in control populations, either in this investigation or in any report in the literature. There has likewise been no report in the literature about the occurrence of 3 per see. classical spike-wave patterns in normal controls, and these patterns were not encountered in this investigation. This again emphasizes that the classical 3 per sec. spikewave pattern and the atypical spike-wave patterns which occur spontaneously, with hyperventilation or photic stimulation in some patients, or with Metrazol, should be held dis- tinctly separate. For these reasons classical 3 per sec. spike-wave discharges associated with a change in the level of consciousness of the patient or focal attacks - - if they are identical with the patients' spontaneous seizures - may be taken as conclusive eridence for the presence of a convulsive disorder when induced by Metrazol.

\section{SUMMARY}

The Metrazol tolerance of 40 normal volunteer subjects was investigated, tolerance was defined as that amount of Metrazol in mg./ kg. at which the slow i.v. administration of the drug had to be stopped because of marked EEG changes, or on account of too marked subjective discomfort. In some instances $500 \mathrm{mg}$. was arbitrarily chosen as the cut-off point. The responses were graded on a 1-4 seale and correlated with symptoms reported in the subject's history and with certain personality attributes of the individual.

Statistically significant correlations were obtained between the Metrazol tolerance, the past history of the individual, and his interest in seeing a psychiatrist for therapentic reasons. EEG changes as a result of Metrazol administration correlated with the state of the resting $\mathrm{EEG}$, the hyperventilation response, and the individual's appraisal of himself as not getting anxious easily. Low tolerance because of marked subjective symptoms during the test correlated with a family history of psychiatric disorders and the subject's appraisal of himself as being ontwardly calm with inner turmoil.

It is concluded that abnormal findings in normal volunteers should not be dismissed as "false positive" results, but as possible indications of overt neuropsychiatric illness. If careful evaluation fails to reveal conclusive evidence, it might be more appropriate to regard the subject as "at present asymptomatic" rather than simply "normal".

\section{RÉSUMÉ}

La tolérance de 40 volontaires normanx envers le Métrazol (cardiazol) a été étudié, la tolérance étant définie par la dose de Métrazol en $\mathrm{mg} . / \mathrm{kg}$. à laquelle l'injection lente par 
voie intraveineuse a dû être abandomnée en raison des altérations EEG marquées ou parce que les sensations subjectives du sujet recevant l'injection devenaient trop désagréable pour permettre la continuation du procédé. Dans quelques instances une dose de $500 \mathrm{mg}$. a été choisie arbitrairement comme point auquel l'injection était arrêtée. Les réponses ont étẻ graduées selon une échelle de 1 à 4 et mises ell corrélation avec des symptômes relevés dans l'histoire du malade et avec certains traits de la personnalité du sujet examiné.

Des corrélations significatives au point de vue statistique ont été obtenues entre le niveau de tolérance envers le Métrazol, l'histoire de l'individu et son intérêt de consulter un psychiatre pour des raisons thérapeutiques. Les altérations électroencéphalographiques résultants de l'administration de Métrazol étaient en corrélation avec les charactéristiques de l'EEG de repos, le type de réponse à l'hyperventilation et le jugement introspectif $d u$ sujet qui se considérait comme n'éprouvant pas facilement de l'anxiété. Un niveau de tolérance bas mis ell évidence par des symptômes subjectifs marqués pendant l'injection du Métrazol était en corrélation étroite avee des antécédents familiaux psychiatriques et avec le jugement introspectif du sujet qui déclarait être un individu ayant un comportement extérieur calme, quoique étant intérieurement tourmenté.

Il est conclu que des résultats anormaux obtenus chez des volontaires normaux ne devraient pas être simplement rejetés comme 《résultats faussement positifs », mais comme indiquant peut-être la présence de troubles neuropsychiatriques manifestes. $\mathrm{Si}$ des recherches soigneuses ne révèlent ancune évidence concluante à cet effet, il est peut-être plus prudent de considérer le sujet comme étant 《asymptomatique pour le présent» plutôt que de simplement le considérer comme étant « normal ».

\section{ZUSAMMENFASSUNG}

40 normale freiwillige Versuchspersonen wurden in Bezug auf ihre Cardiazoltoleranz untersucht. Die Toleranz wurde hier definiert als jene Menge Cardiazols, in $\mathrm{mg} / \mathrm{kg}$, bei welcher die langsame intravenöse Verabreichung des Medikaments, entweder wegen definitiver EEG Veränderungen oder wegen zu starker subjektiver Beschwerden, beendet werden musste. In einigen Faellen wurde die Gesamtdosis willkürlich auf $500 \mathrm{mg}$ beschränkt. Die EEG Befunde und subjektiven Erscheinungen wurden nach einer Skala von 1-4 bewertet und mit Anamnese und gewissen Persönlichkeitscharakteristika der Versuchsperson in Korrelation gesetzt.

Cardiazoltoleranz, Anamnese und der Wunsch der Versuchsperson einen Psychiater aus therapeutischen Gruenden zu sehen, zeigten statistisch bedeutungsvolle Korrelationen. EEG Veränderungen auf Grund der Cardiazolverabreichung waren im Einklang sowohl mit dem Befund im Ruhe-EEG und Hyperventilationsversuch als auch mit dem subjektiven Eindruck der Versuchsperson nicht leicht ängstlich zu werden. Versuchspersonen mit niedriger Toleranz auf Grund starker subjektiver Besehwerden während des Cardiazolversuchs hatten vielfach eine positive Familienanamnese in Bezug auf psychiatrische Erkrankungen und betrachteten sich als äusserlich ruhig aber innerlich stark erregt.

Der Verfasser ist der Ansieht, dass abnormale Befunde bei normalen Versuchspersonen nicht unbedingt lediglich als "falsch positive" Resultate von der Hand gewiesen werden können, sondern vielmehr als eine Indikation auf das eventuelle Vorliegen einer neuropsychiatrischen Erkrankung betrachtet werden sollten. Falls diese Erkrankung nach gründlicher klinischer Untersuchung nicht feststellbar ist, wäre es wahrscheinlich eher angezeigt, wemn man die betreffende Person als "gegenwärtig asymptomatisch" betrachten wïrde, denn als einfach "normal".

The author would like to express his great appreciation to Mrs. Lillian Kelly for the statistical evaluation of the data.

\section{REFERENCES}

Baker, R. N., Klass, D. W. and Walter, R. D. The Metrazol activation of the normal brain. Exhibit American Academy of Neurology Meeting. Boston, Mass., April 1957. 
BLChTHAL, F. and LenNox, M. The EEG effect of Metrazol and photic stimulation in 682 normal subjects. EEG Clin. Neurophysiol., 1953, 5: 545558.

Cole, Nyla J., Hardin Branch, C. H. and Shaw, OrLA M. Mental illness. A survey assessment of community rates, attitudes and adjustments. A.M.A. Arch. Neurol. Psychiat., 1957, 77: 393398.

Cure, C., Rasmussen, T. and Jasper, H. Activation of seizures and electroencephalographic disturbances in epileptic and in control subjects with Metrazol. Arch. Neurol. Psychiat., Chicago, 1949, 59: $691-717$.

Fuglasang-Fredricksen, V. Activation of EEG disturbanees with Metrazol (Pentazol) in epileptics, normals and patients with syneopal attacks. $E E G$ Clin. Neurophysiol., 1952, $4: 471-480$.

Gastaut, H. Combined photic and Metrazol activation of the brain. EEG Clin. Neurophysiol., 1950, 2: $249-261$.
Kershman, J. Combined photie-Metrazol activation in normal subjects and in psychoneurotic and schizophrenie patients. EEG Clin. Neurophysiol., 1951, 3: $377-378$.

Lasagna, L. and von Felsinger. J. M. The volunteer subject in research. Science, 1954, 190: 359-361.

Leighton, D. C. Distribution of psychiatric symptoms in a small town. Amer. J. Psychiat., 1956, 11: 716-723.

Moore, F. T., Kellaway, P. and Kagawa, N. Metrazol activation as a diagnostic adjunct in electroencephalography. Neurology, 1954, 4: 325-338.

Ulett, G. A., Brockman, J. C., Giessre, G. and Johnson, A. Determination of convulsive threshold by photo-pharmacologic stimulation: A study of technique and reliability. EEG Clin. Neurophysiol., 1955, 7 : 597-607.

Ziskind, F., Bercel, N. A. and Friednan, R. Preconvulsive paroxysmal electroencephalographic changes after Metrazol injection. Res. Publ. Ass. nerv. ment. Dis., 1947, 26: 487-501.

Reference: RoDin, E. Metrazol tolerance in a "normal" volunteer population. EEG Clin. Neurophysiol., 1958, $10: 433-446$. 